\title{
Der Gesetzgeber ist gefordert! Ein Vorschlag zur Regelung der Zirkumzision im „Gesetz über die religiöse Kindererziehung“"
}

VB verfassungsblog.de/der-gesetzgeber-ist-gefordert-ein-vorschlag-zur-regelung-der-zirkumzision-im-gesetzber-die-religise-kindererziehung/

Hans Michael Heinig Mo 16 Jul 2012

Mo $16 \mathrm{Jul}$ 2012

Die Entscheidung des LG Köln vom 07.05.2012 in der Rechtssache Wa. 151 Ns 169/11 hat im In- und Ausland ein lebhaftes Echo gefunden [Auf dem Verfassungsblog kommentierten bislang Maximilian Steinbeis, Hans Michael Heinig und Georg Neureither, A.K.]. Deutschland droht nicht weniger als ein veritabler Kulturkampf. Die Zukunft des jüdischen Lebens in Deutschland ist ernsthaft bedroht - nachdem man mit der gezielten Zuwanderung von Juden aus den ehemaligen GUS-Staaten und den damit verbunden erheblichen Integrationsanstrengungen doch gerade diese Zukunft staatlicherseits sichern wollte. Doch auch die Muslime in Deutschland erleben die Entscheidung des Gerichts, vielleicht aber noch mehr die anschließende medial ausgetragene Auseinandersetzung als eine Sarrazinisierung der öffentlichen Meinung in Deutschland und fragen sich, ob die lange Phase weitgerühmter Religionsfreiheitlichkeit und Religionsfreundlichkeit der deutschen Rechtsordnung tempi passati sind.

Der Bundesaußenminister hat die (außen)politische Brisanz des Kölner Gerichtsurteils früh erkannt und erklärt, dass die Entscheidung nicht das letzte Wort in der Sache sein könne. Mit einiger Verzögerung haben sich dann auch anderen Protagonisten aus den politischen Eliten positioniert. Die Bundesregierung, aber auch die Fraktionsspitzen von SPD und Bündnis 90/Die Grünen haben sich inzwischen dafür ausgesprochen, schnell Rechtssicherheit zugunsten der Juden und Muslime in unserem Land zu schaffen, gegebenenfalls durch eine gesetzgeberische Klarstellung. Seitdem werden unterschiedlichste Ansätze für legislatives Handeln diskutiert, u.a. eine Ergänzung des Patientienrechtegesetzes. Dabei wird übersehen, dass es seit den 1920er Jahren bereits ein unmittelbar einschlägiges Gesetzeswerk gibt: Das Gesetz über die religiöse Kindererziehung. Es regelt u.a. Konflikte zwischen den Eltern in rebus religionis, trifft Anordnungen für den Fall der Pflegschaft oder Vormundschaft und bestimmt die Religionsmündigkeit Heranwachsender.

Dieses Gesetz könnte man wie folgt ergänzen:
„3a
Die elterliche Sorgeberechtigung in religiösen Angelegenheiten umfasst auch die Einwilligung in eine von medizinisch qualifiziertem Personal de lege artis durchgeführte Zirkumzision, wenn eine solche nach dem religiösen Selbstverständnis der Sorgeberechtigten zwingend geboten ist. Im Falle einer Vormundschaft oder Pflegschaft findet § 3 Abs. 2 Anwendung."

Die vorgeschlagene gesetzgeberische Klarstellung erfüllt drei Ziele:

- $\quad$ Eine solche Regelung schafft Rechtssicherheit und verhilft der elterlichen Freiheit, über die religiöse Beheimatung ihrer Kinder zu entscheiden, zur effektiven Entfaltung. Mit der ausdrücklichen Zuweisung der Entscheidung zum Bereich der elterlichen Sorgeberechtigung wird seitens des Gesetzgebers verdeutlicht, dass die Eltern rechtswirksam, d.h. die strafrechtliche Rechtswidrigkeit ausschließend, in die Zirkumzision einwilligen können.

- $\quad$ Eine solche Regelung entspricht der staatlichen Schutzpflicht für das gewichtige Rechtsgut der körperlichen Unversehrtheit. Deshalb wird nur die klassische Zirkumzision, d.h. die Beschneidung bei männlichen Personen, als relativ geringfügiger Eingriff in die körperliche Unversehrtheit von der Klarstellung 
erfasst. Die Genitalverstümmelung bei Mädchen oder andere gravierende Eingriffe in die Persönlichkeitsrechte bleiben selbstredend strafbar. Zudem wird die Klarstellung an die Bedingung geknüpft, dass die Beschneidung von medizinisch qualifiziertem Personal de lege artis durchgeführt wird.

- $\quad$ Schließlich sollte eine gesetzgeberische Regelung auf Fälle beschränkt werden, in denen ein staatliches Verbot der Beschneidung zu einem ernsthaften Gewissenskonflikt der Eltern führen würden. Soweit die Beschneidung bloßer Ausdruck von Brauchtum und nicht Ausfluss des als zwingend erlebten religiösen Selbstverständnisses, kann der Gesetzgeber entscheiden, dass das Elterninteresse zurückzustehen hat. Im Zweifelsfall ist das religiöse Selbstverständnis zu plausibilisieren.

Den jüdischen Eltern in Deutschland läuft die Zeit davon - für das Judentum ist eine Beschneidung acht Tage nach der Geburt in der Tradition von Gen 17,12 religiös zwingend geboten. Für die Muslime in Deutschland ist der Zeitdruck mangels fester Altersgrenzen bei der Zirkumzision nicht ganz so gravierend, die Frage, ob man als Muslim, als Muslima (mit den identitätskonstituierenden religiösen Überlieferungen) „zu Deutschland gehört“ aber ähnlich drängend. Der Gesetzgeber ist deshalb aufgefordert, zeitnah und sachgerecht eine gesetzliche Klarstellung zu verabschieden. Das Gesetz über die religiöse Kindererziehung ist dafür der richtige systematische Ort.

Hans Michael Heinig ist Inhaber des Lehrstuhls für Öffentliches Recht, insb. Kirchen- und Staatskirchenrecht an der Georg-August-Universität Göttingen und leitet im Nebenamt das Kirchenrechtliche Institut der EKD.

\section{LICENSED UNDER CC BY NC ND}

SUGGESTED CITATION Heinig, Hans Michael: Der Gesetzgeber ist gefordert! Ein Vorschlag zur Regelung der Zirkumzision im „Gesetz über die religiöse Kindererziehung“, VerfBlog, 2012/7/16, http://verfassungsblog.de/dergesetzgeber-ist-gefordert-ein-vorschlag-zur-regelung-der-zirkumzision-im-gesetz-ber-die-religisekindererziehung/. 